\title{
DE TENDÊNCIA A REALIDADE: O TELETRABALHO E A PROTEÇÃO AOS DIREITOS FUNDAMENTAIS SOCIAIS DO TELETRABALHADOR
}

\author{
FROM TREND TO REALITY: TELE-WORK AND PROTECTION TO \\ THE FUNDAMENTAL SOCIAL RIGHTS OF THE TELE-WORKER
}

\author{
Luiz Fernando Bellinetti ${ }^{1}$ \\ Amanda Machado Sorgi ${ }^{2}$
}

\begin{abstract}
RESUMO
A pesquisa propõe a análise da realidade do teletrabalho e os direitos fundamentais sociais do trabalhador, assim entendidos aqueles constantes dos artigos $7^{\circ}, 8^{\circ}$ e $9^{\circ}$ da $\mathrm{CF}$. A temática é abordada desde a construção doutrinária do teletrabalho enquanto tendência para o futuro até o teletrabalho como realidade, a partir do incremento das TICs nas últimas décadas e diante das medidas de contenção da pandemia da Covid-19, que contribuem mundialmente para a expansão dessa forma de trabalho à distância. A partir do emprego do método dedutivo, o texto verifica a existência de riscos à banalização do teletrabalho, em especial quanto aos direitos que dizem respeito ao tempo de trabalho, ao espaço de trabalho e à ideia de coletivo. Tais direitos, diante da pouca - e, por vezes, contraditória - regulamentação específica do teletrabalho, não devem permanecer desprotegidos, devendo tais aspectos serem compatibilizados com a proteção constitucional aos direitos fundamentais sociais do trabalhador e, agora, do teletrabalhador.
\end{abstract}

\section{PALAVRAS-CHAVE:}

Direitos fundamentais sociais; Teletrabalho; Pandemia da Covid-19; Vedação ao retrocesso social.

\footnotetext{
${ }^{1}$ Possui graduação em Direito pela Universidade Estadual de Londrina (1980), mestrado em Direito das Relações Sociais pela Universidade Estadual de Londrina (1985) e doutorado em Direito pela Pontifícia Universidade Católica de São Paulo (1997). Atualmente é professor associado da Universidade Estadual de Londrina. Tem experiência na área de Direito, com ênfase em Direito Processual Civil, atuando principalmente nos seguintes temas: interesses transindividuais, ações coletivas, ação civil pública, tutela jurisdicional e sentença.

${ }^{2}$ Advogada e professora de Língua Portuguesa (cursando graduação em Letras-Português). Mestranda em Direito Negocial pela Universidade Estadual de Londrina (UEL), bolsista CAPES/DS. Especialista em Direito do Estado (ênfase em Direito Constitucional) pela UEL e em Direito e Processo do Trabalho pela Escola da Magistratura do Trabalho da 9. ${ }^{a}$ Região (Ematra-PR). Graduada em Direito pela UEL. Áreas de interesse: Direito do Trabalho, Direito Processual do Trabalho, Acesso à Justiça e Direito Constitucional.
} 


\begin{abstract}
The research proposes the analysis of the reality of teleworking and the fundamental social rights of the worker, thus understood those contained in articles 7, 8 and 9 of the $\mathrm{CF}$. The theme is addressed from the doctrinal construction of telework as a trend towards the future to telework as a reality, based on the increase in ICTs in recent decades and in view of the measures to contain the Covid-19 pandemic, which contribute worldwide to the expansion of this way of working at a distance. From the use of the deductive method, the text verifies the existence of risks to the trivialization of teleworking, especially regarding the rights that concern working time, work environment and the idea of collective. Such rights, given the little - and sometimes contradictory - specific regulation of telework, should not remain unprotected, and such aspects must be made compatible with the constitutional protection of the fundamental social rights of the worker and, now, of the teleworker.
\end{abstract}

\title{
KEYWORDS:
}

Fundamental social rights; Teleworking; Covid-19 Pandemic; Prohibition against social setback.

\section{INTRODUÇÃO}

As mudanças que ocorrem ao longo da história no modo de vida e de produção das sociedades impactam de forma direta o trabalho humano, aquilo que se entende por trabalho e os meios pelos quais o trabalho pode ser realizado. A análise da História aponta para mudanças trabalhistas significativas com o advento das indústrias, da máquina à vapor, da eletricidade e das inovações tecnológicas. Fora do contexto produtivo, o que acontece com a economia e com a vida em sociedade igualmente afeta o mundo do trabalho e o modo de trabalhar. Existem exemplos recentes, como os impactos sentidos com a Crise estrutural do capital em 2008/2009 e, atualmente, com as medidas de contenção da pandemia da Covid-19 e com uma nova crise que se anuncia.

A sobreposição, hoje, das novas tecnologias e das medidas de contenção da pandemia da Covid-19 possibilitaram que muitos trabalhadores fossem colocados, de forma abrupta, em regime de teletrabalho. O que já era considerado e imaginado para o futuro, mas que ainda conta com uma regulamentação frágil, passou a ser realizado na prática, mudando, provavelmente mesmo para além da pandemia, o que se entende por trabalho. Surge, portanto, o problema de 
como garantir a proteção aos direitos do trabalhador em situação de teletrabalho mesmo diante da regulamentação ainda incipiente sobre o tema.

A partir do problema que se impõe, a pesquisa objetiva analisar a necessária contemporização do teletrabalho aos direitos fundamentais do teletrabalhador, de modo que a expansão do teletrabalho não implique em vedado retrocesso social à classe trabalhadora. Para isso, ao longo dos capítulos que compõem o artigo, pretende-se analisar a transposição do teletrabalho de tendência para realidade verificada no contexto inicial da pandemia da Covid19, os riscos mais urgentes colocados aos direitos do trabalhador na hipótese de mera banalização do teletrabalho, e a necessidade de proteção dos direitos fundamentais sociais do trabalhador também quando em teletrabalho, sobretudo em relação ao tempo de trabalho, ao espaço ou meio-ambiente de trabalho e à preservação da força coletiva, necessária à proteção e luta por ampliação de direitos nas relações de trabalho.

No desenvolvimento da pesquisa, emprega-se os métodos qualitativo e dedutivo, mediante revisão bibliográfica sobre o tema, e apoio em dados e pesquisas divulgados durante o início da pandemia da Covid-19. Enquanto técnica de pesquisa, emprega-se a análise hermenêutica dos direitos garantidos à classe trabalhadora na Constituição Federal e a sua extensão também às hipóteses de teletrabalho.

\section{TECNOLOGIA, O MUNDO DO TRABALHO E PANDEMIA: O TELETRABALHO ENQUANTO TENDÊNCIA E ENQUANTO REALIDADE}

O crescente progresso tecnológico das últimas décadas, caracterizado pelo desenvolvimento e aperfeiçoamento de novas tecnologias de informação e comunicação (TICs), tem modificado a forma como o homem vive em sociedade, relaciona-se com seus iguais e com o meio-ambiente. A dinâmica do mundo do trabalho, permeada por todos esses aspectos, também tem sentido alterações com a criação de novas formas de trabalho e com a repaginação, pela tecnologia, de formas de trabalho já existentes. 
A percepção das mudanças provocadas pela tecnologia no mundo do trabalho não é nova, e já há alguns anos motiva estudos da Sociologia e do Direito a fim de reconhecer as novas formas de trabalho e compatibilizá-las com o arcabouço normativo existente, para que não signifiquem violenta redução de direitos e de conquistas trabalhistas (exemplificativamente, no Brasil, os estudos de: ROBORTELLA, 1994; ANTUNES; BRAGA, 2009; DELGADO, 2015).

Entre as diversas alterações provocadas no mundo do trabalho pelo incremento das TICs, emerge a tendência à desconcentração da fábrica em relação a determinados tipos de trabalho, uma vez que a aceleração tecnológica faz com que nem todos os trabalhadores necessitem estar espacialmente desenvolvendo as atividades nas dependências do empregador (ROBORTELLA, 1994, p. 135; BIESDORF; SANTIAGO, 2011, p. 86).

Para o sociólogo italiano Domenico de Masi, a desconcentração da fábrica possibilita a realização da ubiquidade, pelo menos em relação ao trabalho intelectual. Conforme expõe o autor, a partir das tecnologias disponíveis na sociedade pós-industrial, "o local de trabalho não constitui mais uma variável independente do teorema da organização e o horário rigidamente sincronizado não constitui mais uma exigência real da produção" (MASI, 2000, p. 225).

No contexto da desconcentração, o teletrabalho era apontado enquanto tendência a ser implementada nas próximas décadas, considerando que a descentralização das empresas já apontava que o trabalhador poderia desempenhar suas atividades de qualquer lugar, sendo também possível ao empregador manter o controle e supervisão do trabalho mediante equipamentos telemáticos e informatizados (WULFING; OLIVEIRA, 2013, p. 119).

Nesse sentido, também conclui Maurício Godinho Delgado, em estudo feito sobre o impacto da tecnologia no trabalho humano dentro do contexto capitalista, identificando que as inovações da terceira revolução tecnológica do capitalismo "criaram ou acentuaram formas de prestação laborativa que pareciam estranhas ao tradicional sistema de contratação e controle empregatícios - por exemplo, o teletrabalho e o escritório em casa (home-office)." (DELGADO, 2015, p. 38). 
Diante da identificação dessa tendência, importa compreender o que se entende por trabalho a domicílio e por teletrabalho, que são duas espécies do gênero de trabalho à distância (GARCIA, 2017, p. 93-94).

O trabalho a domicílio trata-se de forma já tradicional de trabalho, habitual antes do surgimento das fábricas e comum, mesmo hoje, em determinadas profissões, implicando que o trabalho seja feito em casa e não na sede do empregador. O teletrabalho, por sua vez, diz respeito ao trabalho que é caracterizado pela prestação de serviços preponderantemente fora das dependências do empregador com utilização das TICs.

Embora, por vezes, o teletrabalho revisite o tradicional exemplo do trabalho a domicílio (conforme COELHO, 2007, p. 335), com ele não se confunde. Isso porque, ainda que possa ocorrer no domicílio do empregado (home-office), essa não é exigência caracterizante do teletrabalho. Nesse sentido, oportuna a distinção feita por Maurício Godinho Delgado:

1) O tradicional trabalho no domicílio, há tempos existente na vida social, sendo comum a certos segmentos profissionais, como as costureiras, as cerzideiras, os trabalhadores no setor de calçados, as doceiras, etc.; 2) o novo trabalho no domicílio, chamado home-office, à base da informática, dos novos meios de comunicação e dos equipamentos elétricos e eletrônicos convergentes; 3) o teletrabalho, que pode se jungir ao home-office, mas pode também se concretizar em distintos locais de utilização dos equipamentos eletrônicos hoje consagrados (informática, internet, telefonia celular, etc.). (DELGADO, 2018, p. 1064).

Posicionamento semelhante se faz presente na diferenciação entre os termos apresentada por Juliana Wulfing e Olga Oliveira, explicando as autoras que o termo "teletrabalhador" designa quem executa suas tarefas de modo remoto, em lugar que não seja a empresa, com o controle e supervisão mediante uso de equipamentos telemáticos e informatizados. É, assim, o empregado fisicamente ausente do local de trabalho, mas presente tecnologicamente, diante da subordinação jurídica realizada pelos meios informatizados (WULFING; OLIVEIRA, 2013, p. 116).

A repaginação do conceito de trabalho à distância e, em especial, a tendência de crescimento do teletrabalho foi reconhecida pela legislação trabalhista no Brasil. Foi o que aconteceu, primeiro, com a adição do parágrafo único ao art. $6^{\circ}$ da Consolidação das Leis do Trabalho (CLT) em 2011, pela Lei 12.551/2011. 
$\mathrm{O}$ artigo, que prevê a igualdade entre o trabalho realizado no estabelecimento do empregador, o trabalho executado a domicílio e o realizado a distância, passou também a reconhecer os meios telemáticos e informatizados como meios de comando e supervisão do trabalho. (BRASIL, 2011).

Mais adiante, em 2017, a Lei 13.467/17 ("Reforma" trabalhista) introduziu na CLT artigos específicos (art. 75-A a art. 75-E) tratando sobre o teletrabalho no Brasil. Entre os artigos, consta a definição de teletrabalho, como sendo: “a prestação de serviços preponderantemente fora das dependências do empregador, com a utilização de tecnologias de informação e de comunicação que, por sua natureza, não se constituam como trabalho externo" (BRASIL, 2017).

Os demais artigos lançam luz sobre qual deveria ser a sistemática do teletrabalho, a aquisição dos equipamentos, a possibilidade de acidentes de trabalho e a transformação de um contrato de trabalho em contrato de teletrabalho. Porém, a disciplina trazida pela "Reforma" está longe de ser detalhada e no estudo da Lei 13.467/17 identificam-se diversas lacunas práticas quanto à realização do teletrabalho (SILVA, 2017; CARELLI, 2017; DIAS; et al., 2018).

Em verdade, a análise dos artigos 75-A a 75-E parece indicar ter o legislador focado em um teletrabalho que existia, em maior escala, apenas enquanto tendência e não enquanto realidade.

O cenário, porém, mudou drasticamente. Com a declaração de pandemia da Coronavirus disease 19 (Covid-19) pela Organização Mundial da Saúde (OMS) em 11 de março de 2020, a desconcentração do trabalho da sede das empresas passou a ser orientação de distanciamento social a fim de reduzir as possibilidades de contágio pelo novo coronavírus. Com isso, mundialmente, trabalhadores foram colocados em situação de trabalho à distância e, diante do atual avanço das TICs, em situação de teletrabalho ou, mesmo, home-office.

Segundo estudo apresentado pela Organização Internacional do Trabalho (OIT/ILO), como resultado das medidas de contenção à Covid-19, na metade do mês de abril de 2020, 59 países já haviam implementado formas de teletrabalho para serviços não-essenciais (ILO, 2020). A mudança é considerável, especialmente diante de relatório anterior da própria OIT, 
apresentado em 2017, que previa uma paulatina adoção das TICs e do teletrabalho para os próximos anos (ILO; EUROFOUND, 2017).

Entre esses 59 países, inclui-se o Brasil. Para lidar com a realidade do mundo do trabalho durante a pandemia, foi editada pela Presidência da República a Medida Provisória (MP) n. ${ }^{\circ}$ 927, em março de 2020. Entre outros temas, a MP disciplinava o teletrabalho, colocado como regime de trabalho alternativo durante a pandemia (artigos $3^{\circ}, 4^{\circ}$ e $5^{\circ}$ da MP).

É claro que o teletrabalho não é uma possibilidade para qualquer tipo de trabalho, nem de adoção igualitária por todos os países. Conforme estudo publicado em junho de 2020 pelo Instituto de Pesquisa Econômica Aplicada (Ipea), a partir dos dados da OIT, identifica-se a "existência de uma relação crescente entre a proporção de empregos que podem ser realizados em casa e o nível de desenvolvimento econômico de um país” (GÓES et al., 2020, p. 2).

Internacionalmente, as pesquisas apontam em sentido semelhante. Conforme exposto em pesquisa feita nos Países Baixos e publicada pelo Institute of Labour Economics, analisando os dados de teletrabalho nas atividades durante o início da pandemia, "low educated workers experience the largest decrease in terms of absolute and relative working hours (-21\%), medium educated workers the second largest decrease $(-13 \%)$, while the decrease is less than $10 \%$ for highly educated workers" ${ }^{3 "}$ (GAUDECKER et al., 2020, p. 12).

Em estudo quantitativo conduzido na Itália, também foi observado que o teletrabalho pode ser uma solução positiva para uma parte considerável dos empregados, sobretudo os trabalhadores que realizam tarefas intelectuais que podem ser feitas de forma autônoma. Todavia, o mesmo estudo identificou um aumento nas horas de trabalho e a geração de um maior nível de estresse decorrente da necessidade de permanência online durante grande parte do dia. A pesquisa ainda confirmou, a par do que aparece na pesquisa do IPEA e no citado estudo dos Países Baixos que o tipo de trabalho e competências do trabalhador podem interferir na qualidade e possibilidade do teletrabalho e serem fatores de discriminação, uma vez que a

\footnotetext{
${ }^{3}$ Trabalhadores com poucos anos de educação experimentaram, no início da pandemia, uma grande redução nos termos de horas trabalhadas (chegando a -21\%), enquanto trabalhadores com médio grau de instrução suportaram a segunda maior diminuição das horas trabalhadas (chegando a -13\%), enquanto a diminuição foi de menos de $10 \%$ entre trabalhadores com alto grau de instrução. (Tradução livre dos autores)
} 
capacidade de adaptação ao teletrabalho varia de acordo com condições pessoais de cada funcionário (BOLISANI et al., 2020, p. 17).

No caso brasileiro, o estudo conduzido pelo IPEA identifica que "o Brasil, pelas características de seu mercado de trabalho, possui, na média, um percentual de pessoas em potencial de teletrabalho de cerca de $22,7 \%$, que corresponde a 20,8 milhões de pessoas" (GÓES et al., 2020, p. 4).

Ainda que se esteja diante, no Brasil, de um em cada quatro trabalhos suscetível ao teletrabalho, estudos indicam que a guinada em direção ao aumento do teletrabalho iniciada durante a pandemia da Covid-19 não se extinguirá com a pandemia. É nesse sentido a opinião do sociólogo Ricardo Antunes, em obra dedicada às mudanças provocadas no mundo do trabalho pelo novo coronavírus e pela crise que se levanta, quando afirma que "o teletrabalho e o home-office mostram-se como modalidades que terão significativo crescimento na fase póspandemia, em praticamente todos os ramos em que puderem ser implantados". (ANTUNES, 2020, p. 28).

Percebe-se, assim, que a pandemia da Covid-19 transformou o que era uma tendência mundial ao teletrabalho em uma realidade mundial de teletrabalho que, ao que tudo indica, diante do atual desenvolvimento das TICs, perdurará mesmo para além das medidas de distanciamento social para contenção do novo coronavírus.

O teletrabalho, porém, encontra na legislação trabalhista infraconstitucional - que tratava o teletrabalho em larga escala enquanto tendência - diversas lacunas e, mesmo, incongruências e incertezas acerca da efetivação dos direitos fundamentais trabalhistas na dinâmica do teletrabalho.

\section{OS DIREITOS FUNDAMENTAIS SOCIAIS DO TRABALHADOR E O CENÁRIO DE TELETRABALHO}


Considerando o cenário atual de expansão do teletrabalho, trazido pela pandemia da Covid-19 como uma realidade que parece "ter vindo para ficar", é necessário que o teletrabalho seja compatibilizado com os direitos fundamentais do trabalhador e com a proteção ao primado do trabalho humano, a fim de que não signifique retrocesso em matéria de direitos sociais. Para tanto, importa o detalhamento desses direitos sociais, da vedação ao retrocesso e dos pontos positivos e negativos ao teletrabalhador que podem advir da realidade de teletrabalho.

\subsection{Os direitos fundamentais sociais do trabalhador e a vedação ao retrocesso social}

A Constituição Federal (CF) concede especial proteção ao valor social do trabalho humano. O tema se faz sentir da integralidade do texto constitucional, estando presente explicitamente no art. $1^{\circ}$, IV, enquanto fundamento da República Federativa do Brasil; no art. $6^{\circ}$, enquanto direito social; no detalhamento dos direitos fundamentais realizado pelos artigos $7^{\circ}, 8^{\circ}$ e $9^{\circ}$ e também no art. 170, caput, enquanto um dos fundamentos da ordem econômica brasileira. (BRASIL, 1988).

Especificamente quanto aos direitos fundamentais do trabalhador, o título II da $\mathrm{CF}$, destinado a tratar dos Direitos e garantias fundamentais, contém o capítulo II, que dispõe sobre os direitos sociais. Entre esses, estão presentes os direitos dos trabalhadores urbanos e rurais $\left(\operatorname{art.} 7^{\circ}\right)$, a possibilidade de sindicalização $\left(\operatorname{art.~} 8^{\circ}\right)$ e a previsão do direito de greve ao trabalhador $\left(\operatorname{art} .9^{\circ}\right)$.

A previsão dos direitos sociais no rol dos direitos fundamentais, a partir do art. $6^{\circ}, \mathrm{CF}$, é comentada por José Afonso da Silva, para quem:

Podemos dizer que os direitos sociais, como dimensão dos direitos fundamentais do homem, são prestações positivas proporcionadas pelo Estado direta ou indiretamente, enunciadas em normas constitucionais, que possibilitam melhores condições de vida aos mais fracos, direitos que tendem a realizar a igualização de situações sociais desiguais. (SILVA, 2016, p. 286).

No rol dos direitos sociais, presentes estão os direitos do trabalhador. Segundo Sarlet, Mitidiero e Marinoni, a previsão das normas atributivas de direitos, liberdades e garantias ao trabalhador, assim como os princípios constitucionais realiza proteção ao trabalho e ao 
trabalhador que tenciona alcançar condições de trabalho dignas para o trabalhador brasileiro, (SARLET; MITIDIERO; MARINONI, 2019, p. 689).

Desse modo, a fim de promover o trabalho em condições dignas, os direitos sociais fundamentais do trabalhador englobam diversos direitos inerentes às relações de trabalho. Conforme enumera José Afonso da Silva, o capítulo constitucional tematiza o direito ao trabalho, o direito à garantia do emprego, os direitos sobre as condições de trabalho, os direitos relativos ao salário, os direitos relativos ao repouso e à inatividade do trabalhador, o direito de proteção aos trabalhadores, os direitos protetivos aos dependentes dos trabalhadores, a participação dos trabalhadores nos lucros e cogestão, a associação e liberdade sindicais e o direito de greve (SILVA, 2016).

O detalhamento realizado pela Constituição da matéria trabalhista tem por objetivo a proteção aos direitos sociais dos trabalhadores, erigidos à posição de direitos fundamentais constitucionais. Conforme James Magno Farias, a inserção dos direitos sociais fundamentais em uma constituição, tal qual feita pela Constituição brasileira, é prova da existência de um Estado democrático, preocupado com a opressão do indivíduo pelo próprio Estado e por grupos que defendam interesses meramente econômicos (FARIAS, 2015, p. 31). Isso porque "os direitos fundamentais sociais [...] não podem ser objeto de abolição efetiva ou tendencial, aplicando-se aos direitos sociais também, ressalvadas eventuais particularidades, o sistema constitucional de limites e de limites de limites". (SARLET; MITIDIERO; MARINONI, 2019, p. 627).

A constitucionalização dos direitos trabalhistas também se relaciona com a interpretação constitucional dos demais ramos do Direito. Sobre o tema, Luís Roberto Barroso explica que:

A ideia de constitucionalização do Direito está associada a um efeito expansivo das normas constitucionais, cujo conteúdo material e axiológico se irradia, com força normativa, por todo o sistema jurídico. A Constituição passa a ser não apenas um sistema em si - com sua ordem, unidade e harmonia -, mas também um modo de olhar e interpretar os demais ramos do Direito. A constitucionalização do Direito se realiza, sobretudo, pela interpretação conforme a Constituição, nas suas múltiplas expressões. (BARROSO, 2018, p. 287).

Outro aspecto da constitucionalização de tais direitos visando à maior proteção e à garantia do trabalho em condições dignas, liga-se ao princípio da vedação do retrocesso social. O princípio, entendido enquanto garantia constitucional explícita, implica na proibição de que a legislação infraconstitucional, ou a interpretação que dela se faz, restrinja o patamar dos 
direitos sociais já consagrados, a fim de proteger os direitos sociais contra possíveis violações perpetradas pelos atores públicos e privados (SARLET; MITIDIERO; MARINONI, 2019, p. $645)$.

Assim, tem-se que o trabalho humano goza de especial proteção e valorização pela CF. Visto como princípio fundamental da República e da ordem econômica, o trabalho trata-se de direito fundamental social, posição igualmente assumida pelo detalhamento das condições de trabalho realizado pelos artigos $7^{\circ}, 8^{\circ}$ e $9^{\circ}$ da $\mathrm{CF}$.

A inclusão de tais direitos no rol dos direitos fundamentais sociais visa ao alcance de condições dignas para o trabalhador, de modo que a previsão constitucional irradia-se pela legislação infraconstitucional, que a ela e ao feixe protetivo que dela emana deve ser atenta e compatível, sendo vedado a redução do patamar dos direitos trabalhistas constitucionalmente assegurados. Tal leitura, como se tratará adiante, também se aplica às novas formas de trabalho propiciadas pelo incremento das TICs, como é o caso do teletrabalho.

\subsection{O cenário de teletrabalho: Pontos positivos e negativos à classe trabalhadora}

A adoção do teletrabalho a partir da pandemia da Covid-19 tem possibilitado uma rediscussão acerca dos direitos hoje assegurados ao teletrabalhador. A opção pelo teletrabalho típico, conforme pensada pelo legislador reformista, choca-se com a realidade do teletrabalho atípico, imposto pelas medidas de contenção da propagação do vírus. A partir disso, na prática, faz evidentes as lacunas deixadas pela regulamentação trazida pela Lei 13.467/17.

Como mencionado, desse embate, os estudos apontam para uma continuidade do teletrabalho, que não poderá implicar em retrocesso aos direitos do trabalhador, sobretudo aos direitos sociais fundamentais presentes na Constituição.

Já desde o início dos anos 2000 os pontos positivos e negativos da adoção do teletrabalho e a relação deste com o patamar mínimo de direitos trabalhistas são discutidos pelos pesquisadores. Na obra "O futuro do trabalho", Domenico de Masi, a partir de um olhar otimista para a expansão do teletrabalho, destaca que dele resultaria: 
maior autonomia, uma menor alienação, uma grande economia de energia, de combustível e de tempo, menos poluição e congestionamento do transito; a vida familiar poderia tornar-se mais alegre com a presença maior dos vários membros; a vida do bairro seria mais intensa, pondo fim ao absurdo desperdício das duplas estruturas (casa e escritório); o preço das áreas urbanas poderia diminuir, pela utilização mais racional dos edifícios; poderia melhorar a vida nas cidades, que cada vez se emaranham mais num inferno de gente a se deslocar sem sentido ou interrupção. (MASI, 2000, p. 261).

Embora realmente a expansão do teletrabalho e, mais especificamente, do teletrabalho a domicílio, possa efetivamente representar uma redução de tempo e dinheiro gastos com deslocamento, eliminar os custos de dupla estrutura e propiciar a revitalização da vida familiar, nem todos os aspectos do aumento do teletrabalho são positivos para a classe trabalhadora.

Nos anos que passaram desde a promulgação da Lei 13.467/17, que iniciou a regulamentação do teletrabalho no direito brasileiro, diversas pesquisas apontaram as dificuldades que o teletrabalho representaria, em especial ao Direito Coletivo do Trabalho, em razão do enfraquecimento da ideia de coletividade que o trabalho isolado poderia gerar. Ainda que o teletrabalho apresente pontos positivos, como possibilidade de incrementar a produção e mesmo os vínculos familiares, as dificuldades se colocam, em geral, diante do isolamento do trabalhador, na fragilização da organização sindical, na dificuldade de realização da inspeção do trabalho pelos órgãos administrativos, o que poderia significar, na prática, em um aumento da exploração do trabalhador (DIAS et al., 2018, p. 70-71).

Em recente análise, considerando a expansão do teletrabalho durante a pandemia da Covid-19, Ricardo Antunes destaca novas questões, evidenciadas nos últimos meses, como a justaposição do trabalho produtivo e reprodutivo e a eliminação das barreiras entre os tempos de trabalho e não-trabalho:

Do ponto de vista empresarial, as vantagens são evidentes: mais individualização do trabalho; maior distanciamento social; menos relações solidárias e coletivas no espaço de trabalho (onde floresce a consciência das reais condições de trabalho); distanciamento da organização sindical; tendência crescente à eliminação de direitos (como já conhecemos nos pejotizados e outras formas assemelhadas, como o pequeno empreendorismo); fim da separação entre tempo de trabalho e tempo de vida (visto que as nefastas metas ou são preestabelecidas ou se encontram interiorizadas nas subjetividades que trabalham); e também o que é de grande importância, teremos mais duplicação e justaposição entre trabalho produtivo e trabalho reprodutivo, com clara incidência da intensificação do trabalho feminino, podendo aumentar ainda mais a desigual divisão sociossexual e racial do trabalho. Por certo, há elementos positivos destacados pela classe trabalhadora, como não precisar fazer os deslocamentos, ter maior flexibilidade de horários, poder se alimentar melhor, etc., mas é sempre bom recordar que se trata de uma relação profundamente desigual entre trabalho e capital, em que o que se perde é sempre muito maior do que aquilo que se ganha. (ANTUNES, 2020, p. 29). 
Diante das questões levantadas por esses e outros autores (KUGELMASS, 1996; COELHO, 2007; WULFING; OLIVEIRA, 2013), parece assistir razão à posição de contemporização entre a nova realidade de teletrabalho e as conquistas trabalhistas já existentes e incorporadas ao ordenamento, em especial aos direitos fundamentais do trabalhador (e, agora, teletrabalhador). Em verdade deve se ter cautela na observação dos pontos positivos e negativos do teletrabalho, diante da possibilidade do trabalho de qualquer localidade e das consequências jurídicas que esse trabalho pode representar, desde a melhora na qualidade de vida até a deterioração das condições de trabalho (BIESDORF; SANTIAGO, 2011, p. 87).

Isso implica que o teletrabalho não pode ser banalizado em detrimento dos direitos fundamentais do trabalho, quer em nome das necessárias medidas de proteção contra a propagação da Covid-19, quer em nome do progresso e da implementação das TICs ao mundo do trabalho. Assim, o princípio da vedação ao retrocesso social deve ser observado também no contexto de expansão do teletrabalho, a fim de garantir que não haja redução dos direitos sociais assegurados à classe trabalhadora, sobretudo aos direitos sociais presentes no texto constitucional (assim considerados os direitos presentes nos artigos $7^{\circ}, 8^{\circ}$ e $9^{\circ}$ da CF).

\section{A CONTEMPORIZAÇÃO DO TELETRABALHO AOS DIREITOS FUNDAMENTAIS DO TRABALHADOR}

Diante da expansão do teletrabalho verificada em escala mundial a partir das medidas de contenção à pandemia da Covid-19, das perspectivas de continuidade dessa modalidade de trabalho e dos riscos identificados caso o teletrabalho seja meramente banalizado, necessário se faz a proteção aos direitos fundamentais do teletrabalhador.

Trata-se esse de esforço alinhado com os princípios constitucionais e de Direito do Trabalho, verdadeiro compromisso do Direito em relação às conquistas sociais. Conforme expôs Robortella, "o direito tem a incumbência de criar mecanismos jurídicos que permitam a assimilação das mutações tecnológicas, para garantir o respeito aos direitos humanos e a melhoria da condição social do trabalhador, como objetivo permanente e valor ético inafastável.” (ROBORTELLA, 1994, p. 151-152). 
Mais que valor ético, diante da eficácia dirigente ou irradiante dos direitos fundamentais sociais, é mesmo dever do Estado a realização dos direitos sociais, além da utilização dessas normas como parâmetro para a aplicação e interpretação do direito infraconstitucional, promovendo a realização e proteção dos direitos sociais. (SARLET; MITIDIERO; MARINONI, 2019, p. 629).

Assim, passa-se a análise dos direitos fundamentais do trabalhador que, pela dinâmica do teletrabalho, parecem estar mais vulneráveis à nova realidade: os direitos ligados ao tempo, ao espaço e à coletividade, os quais devem inspirar, nesse contexto, maior proteção.

\subsection{A proteção ao tempo}

A preocupação quanto ao tempo de trabalho diz respeito à limitação e ao controle de jornada de trabalhadores em situação de teletrabalho. Por não ser realizado nas dependências do empregador, o teletrabalho, se banalizado, pode vir a eliminar as barreiras entre os tempos de trabalho e de não-trabalho, fazendo com que o trabalho se imiscua em todos os momentos da vida do trabalhador, transformando-se, em última análise, no único aspecto desta.

A situação é agravada diante da utilização, no teletrabalho, das TICs, que possibilitam a comunicação e conexão constantes entre trabalhador e empresa, podendo propiciar jornadas exaustivas de trabalho e constante conexão.

Conforme previsão constitucional, são direitos fundamentais sociais dos trabalhadores urbanos e rurais a duração do trabalho normal não superior a oito horas diárias e quarenta e quatro semanais (art. $7^{\circ}$, XIII) e a remuneração do serviço extraordinário superior, no mínimo, em cinquenta por cento à do normal (art. $7^{\circ}$, XVI). (BRASIL, 1988).

Corre em auxílio do teletrabalhador, ainda, a já citada alteração legislativa ocorrida no art. $6^{\circ}$ da CLT em 2011, que passou a expressamente afirmar que "não se distingue entre o trabalho realizado no estabelecimento do empregador, o executado no domicílio do empregado e o realizado a distância, desde que estejam caracterizados os pressupostos da relação de emprego". (BRASIL, 2011). Cabe destacar aqui o posicionamento de Mauricio Godinho Delgado, para quem a nova redação do artigo trouxe o reconhecimento das novas formas de 
subordinação, possibilitando que se reconheça o trabalho à distância como trabalho subordinado, com a presença dos pressupostos da relação de emprego (DELGADO, 2018, p. 1065).

Contudo, se a alteração de 2011 pareceu possibilitar a realização dos incisos do art. $7^{\circ}$ referentes à limitação de jornada ao teletrabalhador, a Lei 13.467/17 ("Reforma” trabalhista), trilhou caminho diverso e excluiu o teletrabalhador da aplicação do capítulo da CLT referente à duração do trabalho (art. 62, III, CLT) (BRASIL, 2017).

A exclusão, porém, não elimina o direito fundamental social de limitação de jornada presente na Constituição nem, tampouco, derrogou o art. $6^{\circ}$ da CLT, que igualou os trabalhadores à distância aos trabalhadores que exercem atividades nas dependências do empregador.

Diante desse panorama, Rodrigo Carelli, em artigo dedicado à análise da jornada do teletrabalhador afirma que "somente será admitida a retirada do limite [de duração da jornada] se ficar provado que a quantidade de tarefas impostas pelo empregador não ultrapasse o disposto na Constituição" (CARELLI, 2017, p. 333).

Para Homero Batista da Silva, as TICs que possibilitam o teletrabalho também possibilitam ao empregador a realização do controle de jornada. $\mathrm{O}$ autor expõe que, caso haja meios possíveis de controle da jornada, quer seja por unidade de produção, fiscalização direta ou meios eletrônicos, não deve importar se o trabalho é realizado dentro da empresa ou não, devendo prevalecer a limitação constitucional de jornada (SILVA, 2017, p. 54).

O posicionamento do autor encontra respaldo no parágrafo único do art. $6^{\circ}$ da CLT, o qual prevê que: "meios telemáticos e informatizados de comando, controle e supervisão se equiparam, para fins de subordinação jurídica, aos meios pessoais e diretos de comando, controle e supervisão do trabalho alheio". (BRASIL, 2011).

A Associação Nacional dos Magistrados da Justiça do Trabalho (ANAMATRA) também aprovou enunciado segundo o qual "são devidas horas extras em regime de teletrabalho, assegurado em qualquer caso o direito ao repouso semanal remunerado" (ANAMATRA, 2018). 
A defesa da limitação da jornada no teletrabalho feita pelos autores e pelo Judiciário é essencial, a fim de preservar a justa remuneração, prevenir o adoecimento de trabalhadores e permitir que o trabalhador exerça outros aspectos da vida humana para além do trabalho.

Conforme explica Otávio Amaral Calvet (2005), a limitação da duração da jornada presente no art. $7^{\circ}$, XIII tem três aspectos. O primeiro deles, econômico, diz respeito ao pagamento do trabalhador, realizado em função de dada quantidade de tempo à disposição do empregador; o segundo deles, ligado à saúde do trabalhador, objetiva prevenir acidentes que podem surgir de jornadas exaustivas. Por fim, o terceiro aspecto visa possibilitar que exista um tempo de vida destinado a que o trabalhador possa conviver com familiares e amigos e realização de atividades de cultura e lazer, isto é, a viabilização de um tempo "para afirmação dos direitos fundamentais individuais da intimidade e da vida privada, muito embora sofra o trabalhador com a falta de cultura de utilização desse tempo pela irradiação da vida produtiva por todos os setores da vida humana" (CALVET, 2005, p. 120).

Os mesmos fatores apresentados se fazem necessários na situação de teletrabalho. Por não haver a ligação do tempo de trabalho ao "tempo na empresa", facilmente as jornadas podem extrapolar as $8 \mathrm{~h}$ diárias implicando em realização de trabalho extraordinário que deixa de ser pago ou mesmo considerado como tal. Como resultado, o trabalhador recebe menos pelo trabalho prestado (sem o respectivo adicional); fica sujeito a acidentes (que igualmente podem ocorrer em local diverso da sede da empresa) e tem a vida invadida pelo trabalho.

É o que analisa Rodrigo Carelli, a partir de relatório "Working anytime, anywhere: the effects on the world of work", apresentado pela OIT e pela Eurofound em 2017. Conforme análise do autor:

O relatório [da OIT e Eurofound] alerta para que os trabalhadores realizando teletrabalho estão expostos a perigos à sua saúde e bem-estar, relacionando-o com fatores de risco psicossocial relacionados com a intensidade do trabalho e longas horas extraordinárias, trazendo impacto negativo em níveis de stress, problemas em relação ao sono e impacto percebido na saúde [...] Há demonstração que parte significante do teletrabalho é realizada em caráter suplementar, levando ao trabalho além das horas legais ou contratuais, frequentemente caracterizando sobretrabalho não pago. $\mathrm{O}$ estudo [da OIT] é enfático em dizer que a maior parte do teletrabalho realizado atualmente nos países pesquisados atrapalha o balanço entre a vida e o trabalho, sendo que este último impacta diretamente o tempo de vida livre. (CARELLI, 2017, p. 330).

Assim, tem-se que o teletrabalho, nos contornos pensados pelo legislador reformista da Lei 13.467, ficaria, a princípio, excluído das normas de duração do trabalho. A previsão, porém, 
não derruba o direito fundamental social à limitação de jornada e percepção de adicional de horas extras, nem altera a igualdade entre o trabalho a domicílio e o trabalho nas dependências do empregador. Filia-se, assim, aos autores aqui expostos, pela defesa da limitação de jornada dos teletrabalhadores, a fim de resguardar a justa remuneração pelo trabalho prestado, a saúde do trabalhador e a possibilidade de exercício dos direitos ao lazer e à desconexão (LEITE, 2019, p. 334), a fim de que o trabalho não resuma a experiência da vida humana do teletrabalhador.

Por fim, cabe mencionar que a limitação de jornada se torna ainda mais relevante na análise quanto ao momento da pandemia da Covid-19 e dos trabalhadores que foram colocados excepcionalmente em teletrabalho sob a égide da MP 927/2020. Isso porque a Lei 13.467/17, responsável por excluir o teletrabalhador das normas da CLT sobre duração do trabalho, prevê o teletrabalho típico, em que há uma opção, uma escolha pelo regime de teletrabalho (art. 75C, CLT).

Na situação da MP 927/2020, não houve uma escolha por parte do trabalhador, mas sim uma imposição do regime de teletrabalho pelo empregador em atenção às medidas preventivas da Covid-19, instituindo espécie de teletrabalho atípico, naturalmente impensado pelo legislador que operou a "Reforma" em 2017.

\subsection{A proteção ao espaço}

Assim como ocorre com o tempo, também o espaço de teletrabalho inspira cautela. $\mathrm{O}$ meio ambiente de teletrabalho deve ser adequado ao desenvolvimento das atividades laborais, a fim de que resguarde a saúde física e psíquica do teletrabalhador. Os maiores desafios colocam-se quando o teletrabalho ocorre em home office, na residência do trabalhador, que deverá passar a ser adequada para a realização da atividade laboral.

O conceito de meio-ambiente trazido pela Constituição é amplo, e contém o meioambiente de trabalho. O art. 200, inciso VIII, estipula, entre as competências do Sistema Único de Saúde (SUS): "colaborar na proteção do meio ambiente, nele compreendido o do trabalho". (BRASIL, 1988). Mais adiante, o artigo 225 da CF garante que: "todos têm direito ao meio ambiente ecologicamente equilibrado, bem de uso comum do povo e essencial à sadia qualidade 
de vida, impondo-se ao Poder Público e à coletividade o dever de defendê-lo e preservá-lo para as presentes e futuras gerações". (BRASIL, 1988).

No rol dos direitos fundamentais sociais, o direito ao meio ambiente do trabalho equilibrado se faz sentir nos artigos $6^{\circ}$ e $7^{\circ}$, XXII, XXIII, XXVIII, XXXIII da Constituição. Em especial, destaca-se o direito à "redução dos riscos inerentes ao trabalho, por meio de normas de saúde, higiene e segurança" (art. $7^{\circ}$, XXII) e o direito ao "seguro contra acidentes de trabalho, a cargo do empregador" (art. $7^{\circ}$, XXVIII). (BRASIL, 1988).

Do conteúdo constitucional em relação ao meio ambiente de trabalho, percebe-se o esforço constitucional em ligar o direito ao meio ambiente de trabalho equilibrado como faceta do direito à saúde (SARLET, MARINONI, MITIDIERO, 2019, p. 657). Para Carlos Henrique Bezerra Leite a concepção constitucional de meio ambiente do trabalho "está relacionada com os direitos humanos, notadamente o direito à vida, à segurança e à saúde. Esses direitos, na verdade, constituem corolários dos princípios fundamentais da dignidade da pessoa humana e da cidadania”. (LEITE, 2019, p. 1084).

Tal aspecto deve ser considerado também pela legislação infraconstitucional. Para Sebastião Oliveira,

\footnotetext{
Essa preocupação de enfoque multidisciplinar para a melhora do ambiente laboral é de suma importância porque o homem passa a maior parte da sua vida útil no trabalho, exatamente no período de plenitude de suas forças físicas e mentais, daí por que o trabalho, frequentemente, determina o seu estilo de vida, influência nas condições de saúde, interfere na aparecia e apresentação pessoal e até determina, muitas vezes, a forma da morte [...] a legislação vem atuando para garantir o meio ambiente de trabalho saudável, de modo a assegurar que o exercício do trabalho não prejudique outro direito humano fundamental: o direito à saúde, complemento inseparável do direito à vida. (OLIVEIRA, 2001, p. 127-128).
}

A Lei 13.467/17, ao regulamentar a realização do teletrabalho no Brasil, considerou, ainda que de forma rasa e deixando uma série de lacunas, a questão de proteção ao meio ambiente de teletrabalho. Para Homero Batista da Silva, o capítulo introduzido na CLT sobre o teletrabalho tem "a virtude de admitir que acidentes de trabalho podem ocorrer, portanto, dentro da casa do empregado e não exclusivamente dentro das dependências do empregador". (SILVA, 2017, p. 56).

As previsões quanto ao meio ambiente de teletrabalho constam dos artigos 75-D e 75-E da CLT. O primeiro, traz que serão previstas em contrato escrito as disposições quanto à 
aquisição, manutenção e fornecimento da estrutura necessária ao trabalho. O artigo prevê, ainda, o reembolso do empregado pelo empregador no custeio de tais equipamentos, o qual é obrigatório e deverá ser feito integralmente pelo empregador, configurando, caso contrário, situação de redução salarial indireta (DIAS et al., 2018, p. 73).

$\mathrm{O}$ art. 75-E, por sua vez, diz respeito ao adoecimento do trabalho, reconhecendo a possibilidade de acidente e doença do trabalho no teletrabalho. Todavia, ainda que tal reconhecimento seja importante, o artigo parece transferir a prevenção ao teletrabalhador, que, após instruído, assinará “termo de responsabilidade comprometendo-se a seguir as instruções fornecidas pelo empregador". (BRASIL, 2017).

Quanto a esta transferência da responsabilidade, Homero Batista da Silva consigna que "a tese de que todos os acidentes tivessem como causa "ato inseguro" do empregado está superada faz muitos anos, impondo-se análise multifatorial para a compreensão dos acidentes e doenças a ele equiparadas”. (SILVA, 2017, p. 56). Com isso, é possível compreender que o termo de responsabilidade não desonera o empregador do dever de zelar pela higidez das condições de trabalho (DIAS et al., 2018, p. 74).

Semelhante entendimento foi adotado pela ANAMATRA, com a formulação de enunciados protetivos ao meio ambiente de teletrabalho. Segundo os enunciados, "O regime de teletrabalho não exime o empregador de adequar o ambiente de trabalho às regras da NR-7 (PCSMO), da NR-9 (PPRA) e do artigo 58, § 1o, da Lei 8.213/91 (LTCAT), nem de fiscalizar o ambiente de trabalho, inclusive com a realização de treinamentos" e "O contrato de trabalho deve dispor sobre a estrutura e sobre a forma de reembolso de despesas do teletrabalho, mas não pode transferir para o empregado seus custos, que devem ser suportados exclusivamente pelo empregador". (ANAMATRA, 2020).

Ainda, mesmo no contexto de teletrabalho, são aplicáveis ao meio ambiente de trabalho as Convenções da OIT de n. ${ }^{\circ}$ 155, 161 e 170, sintonizadas com a proteção do meio ambiente de trabalho e da saúde do trabalhador. Em relatório recente, publicado em 2020, a OIT reconhece os desafios à proteção do meio ambiente de teletrabalho, mas reafirma que o teletrabalhador goza dos mesmos direitos internacionais do trabalho concedidos aos demais trabalhadores: 
his choice makes control by the public authorities and the employer more difficult, as there is a need to balance the exercise of control with the right to the worker's privacy. That does not mean that homeworkers do not have the same entitlement as other workers to occupational safety and health protection. Convention No. 177 provides in Article 7 that national laws and regulations on safety and health at work shall also apply to homework, taking account of its special characteristics, and shall establish conditions under which certain types of work and the use of certain substances may be prohibited in homework for reasons of safety and health ${ }^{4}$. (OIT, 2020, p. 218).

Desse modo, tem-se que, ainda que a "Reforma" trabalhista tenha trazido apenas poucos aspectos sobre o meio ambiente de teletrabalho, a matéria não carece de proteção constitucional, internacional, doutrinária e jurisprudencial. O teletrabalhador faz jus ao mesmo direito fundamental à saúde e direito ao meio ambiente de trabalho equilibrado que os demais trabalhadores.

Na realidade do teletrabalho, inclusive, ganha maior destaque as preocupações ligadas à aquisição e manutenção dos equipamentos - diante do uso das TICs - cujos custos não podem ser repassados ao trabalhador; ligadas à ergonomia do trabalho e adequação do mobiliário - que devem propiciar um trabalho seguro e não propenso a acidentes e adoecimentos e, ainda, também à saúde mental do teletrabalhador.

Quanto à saúde mental, destaca-se que os estudos relacionados ao aumento do teletrabalho indicam grande percentual de realização dessa modalidade de trabalho em tarefas intelectuais, propensas à sobrecarga mental. Nesse tipo de trabalho de alta cognição, o teletrabalho contribui para o aceleramento da mente o estacionamento do corpo, provocando desarmonia que traz, enquanto consequência, patologias psicossomáticas (OLIVEIRA, 2001, p. 128-129).

No contexto da pandemia da Covid-19, em especial, a saúde mental do teletrabalhador inspira ainda maiores cuidados, em decorrência da união do trabalho isolado às restrições ao convívio social. Une-se, aqui, a preocupação do espaço com a preocupação do tempo: é importante observar que o tempo de trabalho não se misture com o tempo de não-trabalho a fim

\footnotetext{
${ }^{4}$ A saúde e segurança do trabalho apresenta riscos desafiadores no caso do trabalho a domicílio. Esse fato se apresenta porque tais trabalhos são realizados na casa do trabalhador ou em local da escolha deste, o que torna a fiscalização pelas autorizadas públicas e pelo empregador mais difícil, uma vez que há necessidade de balancear o exercício do controle empregatício e a privacidade do trabalhador. Isso não significa que os trabalhadores a domicílio não tenham os mesmos direitos relativos à saúde e segurança do trabalho que os demais trabalhadores. A Convenção n. ${ }^{\circ} 177$, em seu art. $7^{\circ}$, estabelece que as leis nacionais e as regulações de saúde e segurança do trabalho também devem se estender ao trabalho a domicílio, levando em conta suas características particulares, estabelecendo condições nas quais certos tipos de trabalho e o manuseio de certos tipos de substancias devem ser proibidos no trabalho a domicilio por razoes de segurança e saúde do trabalhador. (Tradução livre dos autores).
} 
de não se converter na única experiência humana durante este período, o que poderia provocar um aumento do adoecimento mental do teletrabalhador. Nesse particular, oportuna a transcrição da conclusão de Cristophe Dejours, no clássico "A loucura do trabalho": "o defeito crônico de uma vida mental sem saída mantido pela organização do trabalho, tem provavelmente um efeito que favorece as descompensações psiconeuróticas”. (DEJOURS, 1992, P. 122).

\subsection{A proteção ao coletivo}

O teletrabalho, embora, por definição, possa ser realizado em espaços de trabalho compartilhados, também pode se dar na forma de home-office, na qual cada teletrabalhador exerce as suas atividades da própria residência.

O cuidado, aqui, reside no fato de que o trabalho isolado pode enfraquecer os laços de coletividade e solidariedade entre a classe trabalhadora. Não se pode esquecer que muitos dos direitos trabalhistas são conquistados por meio da atuação coletiva dos Sindicatos, da realização de greves e das discussões em assembleias para a aprovação de Convenções e Acordos Coletivos de Trabalho particulares a cada categoria.

A associação sindical também constitui direito fundamental social do trabalhador. A previsão, no art. $8^{\circ}$ da CF, estabelece que "é livre a associação profissional ou sindical" (caput) e que "ao sindicato cabe a defesa dos direitos e interesses coletivos ou individuais da categoria, inclusive em questões judiciais ou administrativas" (inciso III). Ainda, também é igualmente assegurado o direito de greve, previsto no art. $9^{\circ}$, nos seguintes termos: "é assegurado o direito de greve, competindo aos trabalhadores decidir sobre a oportunidade de exercê-lo e sobre os interesses que devam por meio dele defender". (BRASIL, 1988).

A ampliação do teletrabalho, durante a pandemia da Covid-19 e para além dela, portanto, pode fazer com que a ideia de coletividade da classe trabalhadora se perca, esvaziando o papel desempenhado pelo Sindicato na defesa dos interesses transindividuais dos trabalhadores e tornando a defesa de tais interesses excessivamente difícil ou custosa aos trabalhadores individualmente considerados. 
A perda do coletivo, assim, tendo em foco uma relação marcadamente desigual como é a relação travada entre empregado e empregador, pode representar uma perda de direitos ou de possibilidades de manejo de ações coletivas pelos teletrabalhadores.

A Lei 13.467/17 ("Reforma" trabalhista), ao disciplinar o teletrabalho, nada disse a respeito da vida sindical do teletrabalhador ou sobre a realização de greves. É o que apontam Dias, Feliciano, Silva e Toledo Filho, ao analisarem que "cabe ressaltar ao menos dois pontos importantes que deixou o legislador nacional de disciplinar de forma específica: a igualdade de condições para a promoção funcional do teletrabalho e a garantia de tutela ou representação sindical" (DIAS, et al., 2018, p. 74).

Todavia, diante do já citado art. $6^{\circ}$ da CLT, que iguala o trabalhador a domicílio em direitos ao trabalhador que exerce suas funções nas dependências do empregador e considerando que a faculdade de associação sindical e o direito de greve constituem direitos fundamentais sociais do trabalhador, parece não haver razões para não se entender que o teletrabalhador também inspira proteção ao seu direito de sindicalização e de greve.

A fim de que a noção de coletividade, essencial à dinâmica do Direito do Trabalho não se perca no contexto de teletrabalho e, ainda mais especificamente, no contexto da pandemia da Covid-19, as próprias TICs que possibilitam o trabalho remoto podem possibilitar novas formas de proximidade entre os trabalhadores e entre os trabalhadores e os representantes sindicais.

Exemplo é a Lei 14.010, editada em junho de 2020, com vigência até outubro de 2020, que, em seu art. $5^{\circ}$, possibilitou a realização de assembleias por pessoas jurídicas de direito privado por meios eletrônicos, independentemente de previsão nos atos constitutivos. (BRASIL, 2020). Outra inegável tendência é a criação de grupos em aplicativos de mensagens instantâneas para o debate sobre as pautas sindicais de cada categoria.

As alternativas propiciadas pela tecnologia, é claro, não excluem, quando fora do contexto de isolamento social gerado pela pandemia da Covid-19, as formas de reunião tradicionais aos Sindicatos, que, conforme fundamentação exposta, também devem ser acessíveis aos teletrabalhadores. 
Em especial, considerando tratar-se o teletrabalho de uma realidade recente e em cenário de expansão, bem como as diversas lacunas legislativas deixadas em sua regulamentação pela Lei 13.467/17 e as dificuldades que se impõem à preservação dos direitos fundamentais sociais do teletrabalhador, a atuação do Sindicato nesses casos, enquanto legitimado à defesa dos interesses transindividuais do trabalhador e do teletrabalhador é imprescindível.

Diante da carência de detalhamento legal, de uma pandemia inesperada e das previsões de crescimento do telerabalho, os Sindicatos colocam-se, ao lado do Ministério Público do Trabalho (MPT), do Direito Administrativo do Trabalho, da OIT e da Justiça do Trabalho enquanto importantes aliados na defesa dos direitos fundamentais do teletrabalhador.

\subsection{A Atuação do Judiciário, Ministério Público, Direito Administrativo do Trabalho e da OIT}

Posto enquanto realidade, o teletrabalho é uma novidade. Sobre essa realidade há pouca legislação específica, o que não significa que o teletrabalhador esteja fadado a um limbo de ausência de direitos.

É necessário, diante do que foi exposto até aqui, compatibilizar a realidade de teletrabalho - que, em meio a diversos pontos positivos e negativos para a classe trabalhadora, parece ter vindo para ficar, diante do atual desenvolvimento das TICs e das pesquisas realizadas (citam-se, a par do que já foi comentado: GOES et al., 2020; ILO, 2020, 2020 e 2017) - e as conquistas sociais do trabalho, sobretudo aquelas erigidas à posição de direitos fundamentais sociais pela $\mathrm{CF}$, com destaque para os artigos $6^{\circ}, 7^{\circ}, 8^{\circ}$ e $9^{\circ}$.

Entre as previsões desses artigos, inspiram maior cautela os direitos ligados ao tempo do trabalhador, ao espaço de trabalho e ao senso de coletivo da classe trabalhadora. Diante das dúvidas que se colocam e das lacunas legais, a necessária proteção ao teletrabalho deve ser feita por meio do feixe protetivo representado pelos Sindicatos profissionais, pelo MPT, pela fiscalização do trabalho (hoje, contraditoriamente, a cargo do Ministério da Economia), pela Justiça do Trabalho e pela OIT. 
A defesa aos direitos sociais a partir dos órgãos estatais - como são a Justiça do Trabalho, o MPT e a fiscalização do trabalho - está ligada ao dever constitucional de proteção, em caráter preventivo e atendendo ao dever de proteção suficiente, sob pena de ilegal insuficiência de proteção aos direitos básicos do trabalhador (SARLET; MITIDIERO; MARINONI, 2019, p. 629).

Ainda sobre tal conjunção de esforços possibilitada pela CF para auxílio do trabalhador, Maurício Godinho Delgado afirma que:

\begin{abstract}
Esse eficaz sistema constitucional é composto pela nova, significativa e atuante tutela aos direitos individuais da personalidade do trabalhador no ambiente laborativo, que foi estruturada pela própria Constituição. Ou seja, desponta como tão incisiva, abrangente e forte essa nova tutela constitucional, a ser efetivada pelas instituições componentes do sistema trabalhista brasileiro (Ministério Público do Trabalho, Ministério do Trabalho e do Emprego, Justiça do Trabalho, além dos sindicatos), que as empresas, instituições e demais empregadores brasileiros seguramente terão de se adaptar a meios e práticas mais democráticos de exercício do poder empregatício, sob pena de sofrerem irreprimíveis restrições por parte das instituições de suporte do Direito do Trabalho (DELGADO, 2012, p. 1209).
\end{abstract}

Embora a citação acima não considerasse, em 2012, a realidade do teletrabalho, a ela também é aplicável, eis que sob a égide da mesma Constituição. Aos Sindicatos e ao MPT, legitimados à defesa dos interesses transindividuais do trabalhador (e, agora, do teletrabalhador), cabe o olhar para o coletivo, para o caso concreto, para a proteção à saúde física, à saúde mental, à ergonomia e à extrapolação reiterada de jornadas que ameaçam os direitos mais nevrálgicos dos teletrabalhadores. Nesse contexto, essencial também se faz a fiscalização do trabalho, na constatação e atribuição de sanções em casos de irregularidades.

À Justiça do Trabalho, para a qual, diante da previsão de acesso à justiça (art. $5^{\circ}, \mathrm{XXXV}$; art. 114, CF) desaguam as controvérsias envolvendo as relações de trabalho, incumbe, na ausência de legislação detalhada quanto ao teletrabalho, a interpretação dos artigos sobre o tema introduzidos pela Lei 13.467/17 à CLT, sem perder de vista o texto constitucional e os direitos fundamentais sociais dos trabalhadores.

Exemplo dessa atuação são os Enunciados firmados pela ANAMATRA quanto ao teletrabalho, que buscaram a compatibilização entre o texto da Lei $13.467 / 17$ e os direitos constitucionais (ANAMATRA, 2018) e, ainda, as possibilidades de controle de constitucionalidade difuso ou concentrado em relação às leis atuais e que venham a ser editadas. 
À OIT, enquanto órgão internacional tripartite, cabe a defesa dos direitos viscerais do trabalhador na ordem internacional, sendo os principais objetivos da organização a promoção dos princípios fundamentais de Direito do Trabalho, a supervisão e aplicação das normas internacionais sobre o tralho humano, a promoção de melhores empregos com vistas a melhoria de renda da classe trabalhadora, a erradicação da desigualdade social e da discriminação, a ampliação e efetivação da proteção social e o fomento ao tripartismo e ao diálogo social nas questões que envolvem o mundo do trabalho (OLIVEIRA, 2011, p. 242).

As Convenções da OIT, ainda, servem enquanto norte para a aplicação do Direito do Trabalho, sendo, muitas vezes, diante das incertezas e proliferações de alterações trabalhistas, importante esteio para a defesa dos direitos trabalhistas internacionalmente reconhecidos.

\section{CONCLUSÕES}

Por meio da pesquisa realizada, conclui-se que o teletrabalho, antes encarado como uma tendência com certo apelo "futurista", tem se colocado, hoje, uma realidade mundial em contexto de expansão. A aceleração desse processo foi e é propiciada pelo incremento das TICs, que possibilitam novas formas de trabalho, subordinação e controle das atividades dos trabalhadores, inclusive fora das dependências do empregador. Alia-se às TICs o cenário de pandemia provocado pela Covid-19, que inspira medidas de isolamento social que são compatíveis com a desconcentração das empresas.

No contexto da pandemia, as TICs e o teletrabalho foram colocados em prática em diversos países, evidenciando a possibilidade de que algumas ocupações permaneçam em regime de teletrabalho mesmo após a pandemia. A realidade do teletrabalho divide opiniões e possui pontos positivos, podendo, em alguns casos, reduzir gastos, otimizar o tempo, possibilitar ao trabalhador um controle maior de sua rotina e aproximar as pessoas em famílias e comunidades. Contudo, a mera banalização do teletrabalho pode colocar em risco direitos fundamentais sociais da classe trabalhadora e implicar em inaceitável retrocesso social. 
Nessa análise, conclui-se que os direitos fundamentais sociais do trabalhador que inspiram maior cautela diante da realidade do teletrabalho dizem respeito à separação entre o tempo de trabalho e de não trabalho do teletrabalhador, ao espaço e meio-ambiente de teletrabalho e à manutenção da ideia de coletivo no caso de teletrabalho isolado.

A regulamentação, no Brasil, quanto a tais temas especificamente em situação de teletrabalho ainda é incipiente (Lei 12.551/11 e Lei 13.467/17), deixando lacunas e contradições que não devem ser interpretadas de modo a reduzir o patamar dos direitos sociais do trabalhador, esbarrando no princípio de vedação ao retrocesso, sobretudo na situação de excepcionalidade trazida pela pandemia da Covid-19.

Faz-se necessária, assim, a compatibilização do teletrabalho aos direitos e garantias constitucionais, por meio da interpretação da legislação existente à luz dos direitos fundamentais sociais do trabalho e das convenções internacionais, também aplicáveis ao teletrabalhador. Nesse esforço, essencial o exercício do dever de proteção dos órgãos estatais aos direitos sociais e a atuação conjunta dos Sindicatos, Ministério Público do Trabalho, Fiscalização do Trabalho e Justiça do Trabalho em defesa dos direitos trabalhistas, da Constituição e da valorização do trabalho humano, mesmo diante das novas facetas que o trabalho hoje assume e certamente virá a assumir no futuro.

\section{REFERÊNCIAS BIBLIOGRÁFICAS}

ANTUNES, Ricardo. Coronavírus: o trabalho sob fogo cruzado. São Paulo: Boitempo, 2020.

ANTUNES, Ricardo; BRAGA, Ruy. Infoproletários: degradação real do trabalho virtual. São Paulo: Boitempo, 2009.

ASSOCIAÇÃO NACIONAL DOS MAGISTRADOS DA JUSTIÇA DO TRABALHO (ANAMATRA). Enunciados da $2^{\text {a }}$ Jornada de Direito Material e Processual do Trabalho. 2018. Disponível em: https://www.anamatra.org.br/imprensa/noticias/26227-enunciadosaprovados-na-2-jornada-de-direito-material-e-processual-do-trabalho-sao-organizados-portema. Acesso em 21 jul. 2020, às 09h.

BARROSO, Luís Roberto. Curso de direito constitucional contemporâneo: os conceitos fundamentais e a construção do novo modelo. 7. ed. São Paulo: Saraiva Educação, 2018.

BIESDORF, Solange Ines; SANTIAGO, Suely. Reflexões contemporâneas de Direito do Trabalho. Curitiba: Rosea Nigra, 2011. 
BOLISANI, E., SCARSO, E., IPSEN, et al. (2020). Working from home during COVID-19 pandemic: lessons learned and issues. Management \& Marketing, 15(s1), 458-476. https://doi.org/10.2478/mmcks-2020-0027.

BRASIL. Constituição da República Federativa do Brasil de 1988. Brasília: DF, Presidência da República. Disponível em: http://www.planalto.gov.br/ccivil_03/constituicao/constituicao.htm. Acesso em 20 jul. 2020, às $11 \mathrm{~h}$.

BRASIL. Lei n. ${ }^{\circ}$ 12.551, de 15 de dezembro de 2011. Altera o art. $6^{\circ}$ da Consolidação das Leis do Trabalho (CLT), aprovada pelo Decreto-Lei $\mathrm{n}^{\circ} 5.452$, de $1^{\circ}$ de maio de 1943 , para equiparar os efeitos jurídicos da subordinação exercida por meios telemáticos e informatizados à exercida por meios pessoais e diretos. Brasília: DF, Presidência da República. Disponível em: http://www.planalto.gov.br/ccivil_03/_Ato2011-2014/2011/Lei/L12551.htm\#art1. Acesso em 16 jul. 2020, às $11 \mathrm{~h}$.

BRASIL. Lei n..$^{\mathbf{1 3 . 4 6 7}}$, de 13 de julho de 2017. Altera a Consolidação das Leis do Trabalho (CLT), aprovada pelo Decreto-Lei $n^{\circ} 5.452$, de $1^{\circ}$ de maio de 1943 , e as Leis $n^{\circ} 6.019$, de 3 de janeiro de 1974, 8.036, de 11 de maio de 1990, e 8.212, de 24 de julho de 1991, a fim de adequar a legislação às novas relações de trabalho. Brasília: DF, Presidência da República. Disponível em: http://www.planalto.gov.br/ccivil_03/_ato2015-2018/2017/lei/113467.htm. Acesso em 16 jul. 2020, às $11 \mathrm{~h} 15$.

BRASIL. Lei n. ${ }^{\mathbf{0}}$ 14.010, de 10 de junho de 2020. Dispõe sobre o Regime Jurídico Emergencial e Transitório das relações jurídicas de Direito Privado (RJET) no período da pandemia do coronavírus (Covid-19). Brasília: DF, Presidência da República. Disponível em: http://www.planalto.gov.br/ccivil_03/_ato2019-2022/2020/lei/L14010.htm. Acesso em 21 jul. 2020 , às $20 \mathrm{~h} 30$.

BRASIL. Medida provisória (MP) n. ${ }^{\circ}$ 927, de 22 de março de 2020. Dispõe sobre as medidas trabalhistas para enfrentamento do estado de calamidade pública reconhecido pelo Decreto Legislativo $\mathrm{n}^{\circ}$ 6, de 20 de março de 2020, e da emergência de saúde pública de importância internacional decorrente do coronavírus (covid-19), e dá outras providências. Disponível em: http://www.planalto.gov.br/ccivil_03/_ato2019-2022/2020/Mpv/mpv927.htm. Acesso em 18 jul. 2020, às $15 \mathrm{~h}$.

CALVET, Otávio Amaral. A eficácia horizontal imediata do direito ao lazer nas relações de trabalho. Dissertação (Mestrado em Direito) - Faculdade de Direito, Universidade de São Paulo. São Paulo, 2005.

CARELLI, Rodrigo. O teletrabalho. In: SOUTO MAIOR, Jorge Luiz; SEVERO, Valdete Souto (coords.). Resistência: aportes teóricos contra o retrocesso trabalhista. São Paulo: Expressão Popular, 2017.

COELHO, Leila Gonçalves Gomes. Revisitação, via teletrabalho, ao conceito de trabalho a domicílio. In: DALLEGRAVE NETO, José Affonso; GUNTHER, Luiz Eduardo; POMBO, Sérgio Luiz da Rocha (coords.). Direito do Trabalho: reflexões atuais. Curitiba: Juruá, 2007. 
DIAS, Carlos Eduardo Oliveira; FELICIANO, Guilherme Guimarães; SILVA, José Antônio Ribeiro de Oliveira; TOLEDO FILHO, Manoel Carlos. Comentários à lei da Reforma Trabalhista: Dogmática, visão crítica e interpretação constitucional. 2. ed. São Paulo: LTr, 2018.

DEJOURS, Cristophe. A loucura do trabalho: estudo de psicopatologia do trabalho. 5. ed. São Paulo: Cortes, 1995.

DELGADO, Mauricio Godinho. Curso de Direito do Trabalho. 17. ed. São Paulo: LTr, 2018.

DELGADO, Maurício Godinho. Capitalismo, trabalho e emprego. 2. ed. São Paulo: LTr, 2015.

DELGADO, Maurício Godinho. Curso de Direito do Trabalho. 11. ed. São Paulo: LTr, 2012.

FARIAS, James Magno. Direito Constitucional do Trabalho. São Paulo LTr, 2015.

GARCIA, Gustavo Filipe Barbosa. Reforma trabalhista: Análise crítica da Lei 13.467/17. 2. ed. Salvador: Juspodivm, 2017.

GAUDECKER, H.; HOLLER, R.; JANYS, L et al. Labour Supply in the Early Stages of the COVID-19 Pandemic: Empirical Evidence on Hours, Home Office, and Expectations. IZA (Institute of Labour Economics) DP No. 13158, April 2020. Disponível em: https://www.iza.org/publications/dp/13158/labour-supply-in-the-early-stages-of-the-covid-19pandemic-empirical-evidence-on-hours-home-office-and-expectations. Acesso em 02 abr. 2021, às 11 h.

GÓES, Geraldo Sandoval; MARTINS, Felipe dos Santos; NASCIMENTO, José Antônio Sena do. Potencial de teletrabalho na pandemia: um retrato no Brasil e no mundo. Carta de conjuntura. n. ${ }^{\circ}$ 47, segundo trimestre de 2020. Disponível em: https://www.ipea.gov.br/portal/images/stories/PDFs/conjuntura/200608_nt_cc47_teletrabalho. PDF. Acesso em 16 jul. 2020, às 13h.

INTERNATIONAL LABOUR ORGANIZATION (ILO). Promoting employment and decent work in a changing landscape. 2020. Disponível em: https://www.ilo.org/ilc/ILCSessions/109/reports/reports-to-theconference/WCMS_736873/lang--en/index.htm. Acesso em 21 jul. 2020, às 20h.

INTERNATIONAL LABOUR ORGANIZATION (ILO). Working from Home: Estimating the worldwide potential. Abr. 2020. Disponível em: https://www.ilo.org/wcmsp5/groups/public/---ed_protect/---protrav/--travail/documents/briefingnote/wcms_743447.pdf. Acesso em 16 jul. 2020, às $15 \mathrm{~h}$.

INTERNATIONAL LABOUR ORGANIZATION (ILO); EUROFOUND. Working anytime, anywhere: The effects on the world of work. Publications Office of the European Union, Luxembourg, and the International Labour Office, Geneva, 2017. Disponível em: https://www.ilo.org/wcmsp5/groups/public/---dgreports/---dcomm/---

publ/documents/publication/wcms_544138.pdf. Acesso em 20 jul. 2020, às 20h. 
KUGELMASS, Joel. Teletrabalho: novas oportunidades para o trabalho flexível. São Paulo: Atlas, 1996.

LEITE, Carlos Henrique Bezerra. Curso de Direito do Trabalho. 11. ed. São Paulo: Saraiva Jur, 2019.

MASI, Domenico de. $\mathbf{O}$ futuro do trabalho: Fadiga e ócio na sociedade pós-industrial. 4. ed. Brasília: Editora UnB, 2000.

OLIVEIRA, Sebastião Geraldo. Proteção jurídica à saúde do trabalhador. 3. ed. São Paulo: LTr, 2001.

OLIVEIRA, Lourival José de. Direito do Trabalho segundo o princípio de valorização do trabalho humano. São Paulo: LTr, 2011.

ROBORTELlA, Luiz Carlos Amorim. O moderno Direito do Trabalho. São Paulo: LTr, 1994.

SARLET, Ingo Wolfgang; MARINONI, Luiz Guilherme; MITIDIERO, Daniel. Curso de Direito Constitucional. 8. ed. São Paulo: Saraiva Jur, 2019.

SILVA, Homero Batista Mateus da. Comentários à Reforma Trabalhista: Análise da Lei 13.467/17 artigo por artigo. São Paulo: Revista dos Tribunais, 2017.

SILVA, José Afonso da. Curso de Direito Constitucional Positivo. 39. ed. São Paulo: Malheiros, 2016.

WULFING, Juliana; OLIVEIRA, Olga Maria Boschi Aguiar. Os caminhos da Consolidação das Leis do Trabalho: do Trabalho em Domicílio ao Teletrabalho. In: CAVALCANTE, Jouberto de Quadros Pessoa; VILLATORE, Marco Antônio César (orgs.). CLT 70 anos de Consolidação: Uma reflexão social, econômica e jurídica. São Paulo: Atlas, 2013.

Data de Submissão: 07/12/2020

Data de Aceite: 18/03/2021 